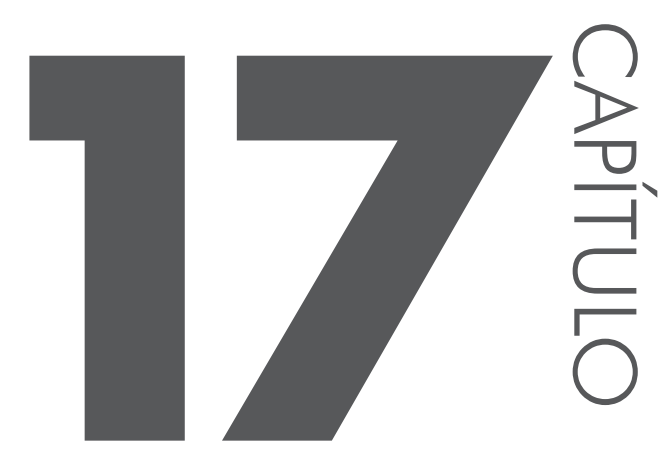

\title{
Língua e poder nos mundos da vida e da arte: diálogos entre Brasil e Angola
}

\section{Cristine Gorski Severo}

Universidade Federal de Santa Catarina

Este capítulo visa a problematizar e analisar comparativamente o papel político da língua, no Brasil e em Angola, à luz de uma articulação entre reflexões literárias e linguísticas. No campo dos estudos da linguagem, verifica-se uma discrepância entre a maneira como os estudos literários têm se dedicado à produção de chaves interpretativas preocupadas com questões de (des)colonização, diáspora e deslocamentos culturais (SAID, 1995; BHABHA, 2003; HALL, 2009) e a forma como a Linguística, enquanto campo do saber, tem se mobilizado pelo tema. Essa discrepância entre os interesses da Literatura e da Linguística pela experiência (des)colonial nos leva a indagar a respeito do papel político de ambos os campos na construção de determinadas "estruturas de atitudes e referências" (SAID, 1995), ou "regimes de verdade" (FOUCAULT, 1999; SHOHAT; STAM, 2006) sobre as línguas. 


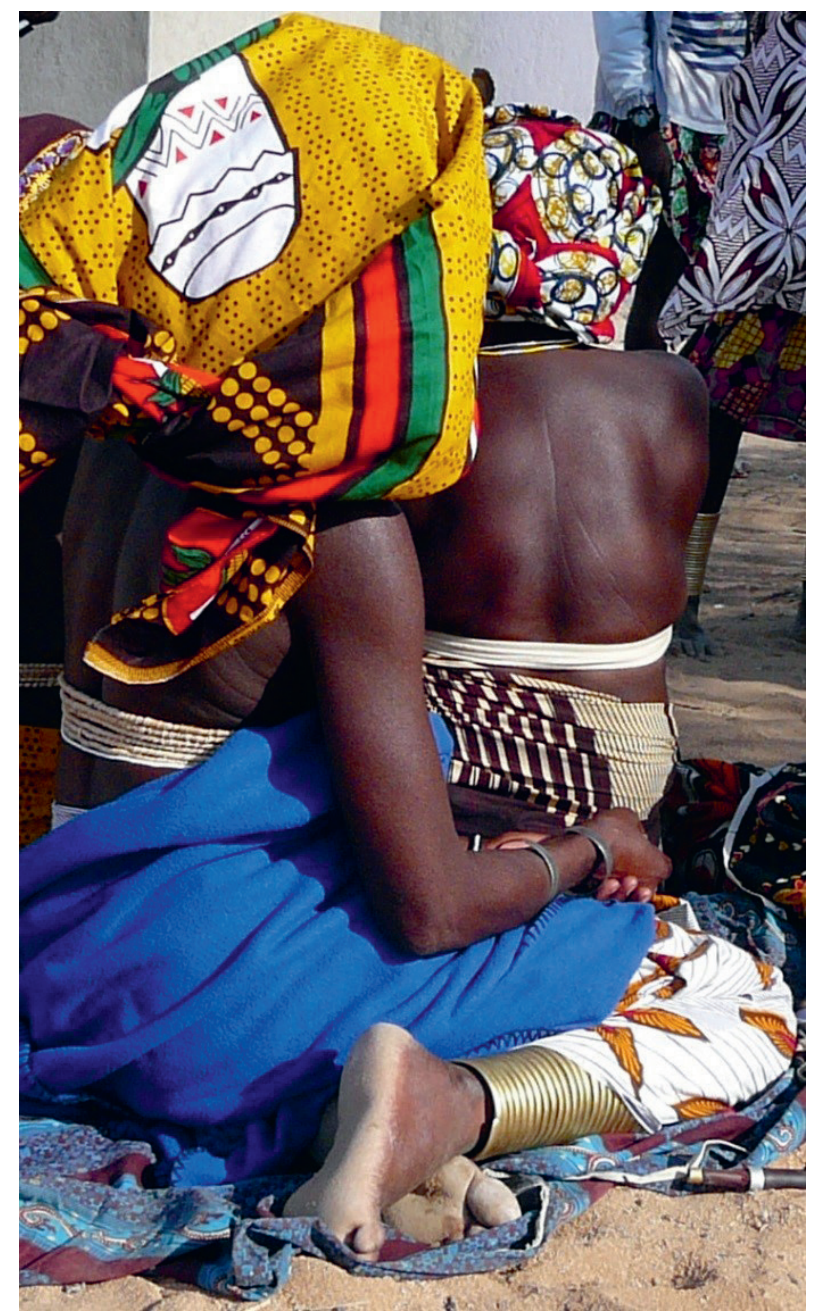

Figura 17.1 - Mulheres do Kuroca. Fonte: Foto de Ilka Boaventura Leite, 2012.

São vastos os trabalhos literários que analisam o papel estético e político da hibridização das línguas na construção de discursos e práticas de resistência, interculturais e pós-coloniais (SAID, 1995; BHABHA, 2003; THION'G, 2004; ABDALA JÚNIOR, 2004; GLISSANT, 2005; entre outros). A título de exemplificação, ao adicionarmos a expressão "literatura pós-colonial” no sistema de busca Google, identificamos cerca de cinco mil ocorrências; por outro lado, ao fazermos a mesma busca usando o sintagma "linguística pós-colonial”, visuali- 
zamos um total de oito ocorrências. ${ }^{89}$ Esse simples exemplo é bastante ilustrativo da disparidade de ambas as áreas do saber em relação à temática colonial e pós-colonial. Essa disparidade deve ser fortemente problematizada, especialmente porque vivemos um contexto que é fruto de experiências colonizadoras recentes, cujas ressonâncias ainda ecoam na esfera acadêmica, entre outras esferas. Além disso, ao propormos estabelecer diálogos acadêmicos com Angola, considera-se essencial uma compreensão histórico-política que permita contextualizar as línguas e as práticas linguísticas, em uma dada dinâmica sócio-histórica, cultural e política. A partir disso, defendemos que um olhar crítico e reflexivo sobre a língua deve, necessariamente, inseri-la nas práticas sociais. Essa visão politicamente contextualizada em Linguística tem sido defendida por uma série de pesquisadores que, de certa maneira, foram afetados pelas experiências coloniais e os jogos de poder. Muitos desses pesquisadores se vinculam ao que tem sido rotulado como Linguística Colonial, que agrupa trabalhos comprometidos com revisões teórico-metodológicas à luz da questão colonial e pós-colonial (SEVERO; MAKONI, 2015; DEUMERT, 2010; MAKONI; PENNYCOOK, 2006; MARIANI, 2006; MAKONI; MEINHOF, 2004; IRVINE, 2008; RAJAGOPALAN, 2008 e 2012; MARIANI, 2006; ERRINGTON, 2001; FARDON; FURNISS, 1993; PHILLIPSON, 1992).

Consideramos que uma abordagem comprometida com a história colonial deve considerar as ressonâncias coloniais e as relações de poder inscritas em dinâmicas linguísticas modernas, especialmente diante da construção das ideias de nação e de nacionalismo. Nesse contexto, embora cada nacionalismo seja "um projeto histórico e social particular”, há que se considerar uma tendência das nações a imitarem "um mecanismo ocidental para atingirem os seus intentos em termos de discurso totalizante" (SÁ, 2012, p. 154-155). Essa imitação produz efeitos perversos, pois tende a homogeneizar os diferentes em prol da ideia de unidade ou de diferenciar os iguais em busca de um maior controle e governo das pessoas. E a língua assume papel político nesse processo de homogeneização e agrupamento. Como contradiscurso, há aqueles que, politicamente, defendem uma descentralização administrativa do Estado em busca de políticas pluralistas e interculturais (BEMBE, 2013).

Para ilustrar a discussão proposta no capítulo, serão consideradas as experiências e os discursos (pós-)coloniais no Brasil e em Angola, dois países que compartilharam uma relação colonial intensa, instaurada, principalmente, no contexto da escravização africana: "desde o século XVI, surge um espaço aterritorial, um arquipélago lusófono composto dos enclaves da América portuguesa e

89 Pesquisa realizada em 20 de janeiro de 2016. 
das feitorias de Angola" (ALENCASTRO, 2000, p. 9). Sobre a relação intrínseca entre esses dois países, nos alinhamos à perspectiva do escritor e antropólogo Ruy Duarte de Carvalho: "[...] tanto Angola como o Brasil, no que diz respeito a passados discerníveis, não dá de fato para entender um sem o outro" (2010, p. 277).

A título de uma breve contextualização histórica, dados do $\mathrm{IBGE}^{90}$ revelam que cerca de quatro milhões de homens, mulheres e crianças africanos desembarcaram em solo brasileiro. A origem dos africanos é variada, embora grande parte seja oriunda das atuais regiões de Angola e Costa do Marfim, sendo que Angola se tornou alvo central no comércio de escravizados durante os séculos XVI e XIX, totalizando, por exemplo, 1.285.900 africanos trazidos ao Brasil entre 1701 e 1810 (IBGE). Os povos africanos trazidos ao Brasil foram agrupados em dois grandes conjuntos étnicos - os sudaneses, oriundos da África ocidental, e os bantos, oriundos da África equatorial e tropical. Dentre esses grupos, a presença bantu foi expressiva na formação linguístico-discursiva do Brasil, incluindo as línguas quicongo, quimbundo e umbundo (MENDONÇA, 2012 [1935]; CASTRO, 2001). Compreendemos, contudo, que tais estatísticas e classificações étnicas podem ser complicadas, uma vez que nem sempre representam a complexidade da realidade local.O capítulo se estrutura da seguinte maneira: inicialmente, discorre-se, de forma exemplificada e comentada, sobre papel político da língua nos contextos literários e linguísticos, bem como sobre o papel dos intelectuais na construção e validação de certas concepções de língua; em seguida, apresenta-se e discute-se o conceito de hibridismo em relação aos dois campos teóricos, explorando seu potencial político, seja nos estudos literários, seja nos estudos linguísticos. As duas seções apresentam exemplos dos contextos brasileiro e angolano. $\mathrm{Na}$ sequência, há a conclusão.

\section{Língua e poder nas esferas literária e linguística}

A busca por uma breve aproximação entre Linguística e Literatura nos ajuda a compreender os limites e desafios enfrentados pela primeira diante de indagações de cunho político e ético feitas pelo campo literário sobre a língua e o texto. O distanciamento entre as duas áreas se evidencia pelo "objeto" que cada uma reivindica/produz: enquanto a Linguística tem se ocupado de enunciados cotidianos, a Literatura tem se devotado aos enunciados estéticos. Temos, aqui, uma configuração aparentemente dicotômica entre mundo da vida e mundo da arte (BAKHTIN, 1919), como se ambos não tivessem obrigação de se articularem

90 Instituto Brasileiro de Geografia e Estatística. Informações disponíveis em <http://brasil500anos.ibge.gov.br/territorio-brasileiro-e-povoamento/negros>. Outras informações estatísticas podem ser localizadas em <http://www.slavevoyages.org/>. 
mutuamente. Compreendemos que os enunciados ficcionais - pelo triplo distanciamento que produzem em relação ao autor, contexto e ao leitor - assumem uma certa autonomia que se torna condição necessária para uma recriação do mundo e reinterpretação de si diante do texto (RICOEUR, 1981). Nesse âmbito, o texto ficcional assume uma potência ética capaz de levar os sujeitos a processos de ressignificação e ressubjetivação.

A despeito das cisões entre as áreas - e a reivindicação, por alguns literatos, da autonomia estética do texto literário em relação ao contexto -, nos alinhamos às reflexões do Círculo de Bakhtin que, a depender do gênero literário em questão, propõe uma aproximação entre arte e vida. Voloshinov (1926), por exemplo, defende que a dimensão estética é uma variedade da vida social e, portanto, está sujeita às mesmas influências que outros fenômenos artísticos. Assim, nos apoiamos no pensamento bakhtiniano, quando Bakhtin afirma que "o poeta deve compreender que a sua poesia tem culpa pela prosa trivial da vida, e é bom que o homem da vida saiba que a sua falta de exigência e a falta de seriedade das suas questões vitais respondem pela esterilidade da arte" (BAKHTIN, 2003 [1919], p. XXXIV). Com base nessas reflexões, acreditamos que Linguística e Literatura podem estabelecer diálogos profícuos e engajados em torno de reflexões políticas sobre a língua, seja no âmbito estético, seja no contexto dos usos concretos e cotidianos.

A língua - como produto de práticas sociais cotidianas e/ou estéticas - tem ocupado papel político central no contexto das problematizações e das resistências contra os regimes colonizadores. No âmbito literário, uma série de intelectuais engajados nas lutas de descolonização se apropriaram da literatura como lugar de construção de discursos políticos e de resistências contra relações de dominação e opressão colonial. No Brasil, o período literário que marcou as discussões sobre a produção de uma arte descolonizada e "própria" se vincula ao Modernismo (1922-1945), período em que artistas - como Mário de Andrade, Oswald de Andrade, Graciliano Ramos, José Lins do Rego, Erico Verissimo, Jorge Amado, Guimarães Rosa - produziram interpretações e apropriações dos estilos e discursos estéticos eurocêntricos, nativizando-os.

Exemplificando os usos políticos da língua no Brasil do Modernismo, Oswald de Andrade redigiu o Manifesto Pau-Brasil (1924), ${ }^{91}$ em que defende "a língua sem arcaísmos, sem erudição. Natural e neológica. A contribuição milionária de todos os erros. Como falamos. Como somos”. Já no Manifesto Antropofágico (1928), Oswald de Andrade faz uso intertextual de um poema indígena: "Catiti

91 Os Manifestos estão disponíveis em http://www.ufrgs.br/cdrom/oandrade/oandrade.pdf. Acesso em 23 jan. 2016. 
Catiti / Imara Notiá / Notiá Imara / Ipeju”, e propõe que “já tínhamos o comunismo. Já tínhamos a língua surrealista. A idade de ouro". Dessa forma, o poeta funde, esteticamente, língua e poder, apontando para o papel do uso das línguas locais (indígenas) como forma de manifestação cultural e política, em busca de uma voz própria. A antropofagia torna-se, então, uma categoria estética e política poderosa, que hibridiza modelos estéticos e línguas em busca de uma dada brasilidade, ao estilo de "Tupi, or not tupi that is the question". Com isso, produz-se um texto bivocalizado e internamente dialogizado (BAKHTIN, 1934-1935), em que memórias coloniais são postas em diálogo, em um confronto entre as vozes "locais" e as vozes "dominantes". Outro texto brasileiro que vale mencionar, pela tentativa de legitimar uma língua hibridizada (o português brasileiro), é a Gramatiquinha (1927-1929) de Mário de Andrade, uma mistura entre gramática e texto ficcional, que integrou um projeto nacional de definição do Brasil e da sua norma linguística. Esse material defendia o reconhecimento de uma série de traços considerados próprios da fala brasileira em oposição a um padrão lusitano de língua: "ora aplicando o caso à língua o que a gente tem de fazer é isso: ter a coragem de falar brasileiro sem si amolar com a gramática de Lisboa" (ANDRADE apud PINTO, 1990, p. 49). Defendendo-se de acusações de que queria inventar uma língua brasileira, Mário de Andrade afirmou: “[...] muita gente, até meus amigos, andaram falando que eu queria bancar o Dante e criar a língua brasileira. Graças a Deus não sou tão iguinorante nem tão vaidoso. A minha intenção única foi dar a minha colaboração a um movimento prático de libertação importante necessária” (ANDRADE apud PINTO, 1990, p. 50).

Ressalta-se que essa defesa de uma língua própria - diferente dos padrões lusitanos - foi correlata à promoção de discursos e práticas nacionalistas no Brasil, que se intensificaram na Era Vargas (1930-1945), quando muitos daqueles intelectuais vinculados ao movimento modernista, dentre outros pensadores, foram cooptados por Getúlio Vargas para fins de construção e consolidação de uma dada memória e representação cultural brasileira. E assim:

A ideia é a de que a revolução literária, pondo em cheque os modelos estéticos importados, estaria completa com a revolução política do Estado Novo, cujo objetivo seria o de combater os modelos políticos tidos como alienígenas, como o liberalismo e o comunismo. O ideal da brasilidade e da renovação nacional é, então, apresentado como o elo comum que viria unir as duas revoluções: a artística e a política. (VELLOSO, 1987, p. 43).

Foi dessa maneira que o Ministério da Educação, sob liderança de Gustavo Capanema, enlaçou Mário de Andrade, Carlos Drummond de Andrade e Portinari, entre outros (VELLOSO, 1987). Além disso, o modernismo brasileiro também 
influenciou nacionalismos africanos, em sintonia com as ideias das elites de Cabo Verde e de Angola (SÁ, 2012; CUNHA, 2011).

Já no contexto angolano, podemos mencionar alguns intelectuais e escritores que contribuíram, de diferentes maneiras, para os movimentos de libertação nacional nos anos 1950-1970, como Agostinho Neto, Luandino Vieira, Manuel dos Santos Lima, Pepetela, Ruy Duarte de Carvalho, Uanhenga Xitu, Ernesto Lara Filho, Antônio Jacinto, Antônio Cardoso, Francisco Fernando da Costa Andrade e Ana Paula Tavares. Salienta-se que muitos desses intelectuais estudaram em Portugal, fato que favoreceu a construção, por um pequeno grupo, de um pensamento de libertação africana, pan-africanista, que extrapolava os limites territoriais, embora focalizasse o papel da construção do nacionalismo angolano e da denúncia das violências coloniais como motor das lutas. Alguns desses intelectuais sofreram o peso da vigilância portuguesa, sendo torturados e aprisionados (CUNHA, 2011), como Luandino Vieira, Uanhenga Xitu e Agostinho Neto, que foram presos em Tarrafal, Cabo Verde. Nessa prisão, Vieira redigiu No Antigamente, na Vida e Luuanda, e Xitu começou a escrever a obra O Mestre Tamoda. Nessas obras, a língua portuguesa foi trabalhada esteticamente para inscrever sentidos políticos de crítica ao colonialismo português. Os gêneros literários escritos pelos autores giravam em torno do romance, das crônicas e da poesia. Dentre os escritores angolanos que exploraram as relações históricas entre Angola e Brasil, estão Ruy Duarte de Carvalho e Lara Filho.

Embora o foco deste capítulo não seja detalhar os usos estilísticos feitos por autores angolanos em seus escritos literários referentes ao uso da língua portuguesa e das línguas africanas - consolidando modalidades hibridizadas de línguas, estilos e gêneros literários - procura-se realçar alguns aspectos considerados importantes para a discussão sobre o papel político da língua nas esferas da arte e da vida. Inicialmente, salienta-se a força criativa e política de gêneros orais, como provérbios e narrativas, especialmente em "um país em que a tradição oral é o domínio de expressão criativa de muita gente" (CARVALHO, 2008, p. 54). Paralelamente, cabe mencionar os usos políticos feitos pela colonização portuguesa de um aparato burocrático sofisticado (centrado na escrita), que ajudou a produzir valorações negativas em relação ao papel político da oralidade dos povos africanos. Tal sofisticação tem relação com a manutenção de relações hierarquizadas e autoritárias de poder: "os efeitos do fascismo do tipo ibérico na tradição burocrática de Angola foram particularmente profundos e duradouros. [...] A combinação de colonialismo, fascismo e catolicismo criou uma veneração pela ordem e pela autoridade de que Angola nunca conseguiu se libertar" (BIRMINGHAM, 2003, p. 207-208). Assim, entre a rigidez burocrática e a fluidez literária, operam relações de poder diferentes e intensas, que usam a escrita como signo político.

Retomando o papel dos provérbios - como gêneros que veiculam saberes e 
valores em prol de uma vida compartilhada -, salienta-se a sua importância na construção de um sentimento de pertencimento, afinal: "as ideologias encarnadas nestes gêneros afectam o comportamento, as decisões e as acções das pessoas [...] podem desempenhar um papel determinante na implementação dos ideais do renascimento africano" (ZOUNMÈNOU 2012, p. 378). Não foi à toa, segundo Zounmènou, que muitos políticos africanos da primeira geração usaram provérbios em seus discursos para legitimar suas ideias e criar uma aproximação maior com a vida política das comunidades. Não por acaso, o escritor angolano José Luis Mendonça (2014), ${ }^{92}$ vinculado à nova geração literária angolana, caracterizou alguns escritos de Agostinho Neto como provérbios, pois veiculavam mensagens com tons de conselho, ensinamento, persuasão e convencimento, criando uma ideia - ainda compartilhada pela memória oral angolana - politicamente coesa de construção de uma comunidade nacional. É assim que "os provérbios e contos surgem como ferramentas sociopolíticas com fins de controle social. [...] Abordam a vida diária, bem como a arte de governação no seio das comunidades" (ZOUNMÈNOU, 2012, p. 379).Em outros contextos geopolíticos africanos, onde o engajamento com as lutas de independência também mobilizou uma série de intelectuais, importante mencionar o papel político da língua nas lutas de resistência e de descolonização. Exemplificando, Franz Fanon (2008 [1952]), no texto $O$ negro e a linguagem, defende a relação entre língua, identidade e política: "falar é estar em condições de empregar um certa sintaxe, possuir a morfologia de tal ou qual língua, mas é sobretudo assumir uma cultura, suportar o peso de uma civilização" (p. 33). Percebe-se uma concepção de língua que extravasa os limites estruturais para incorporar a historicidade e a subjetividade. Fanon nos revela que, no contexto político, o que conta como língua diz respeito às experiências compartilhadas e às valorações e usos sociais e político feitos dela e com ela. Por exemplo, o autor aponta para a maneira como o "sotaque" e a "pronúncia" se tornaram lugares de avaliação e julgamento do outro, em que o maior ou menor domínio da língua do colonizador (seja o francês, inglês ou português) era tomado como índice de classificação, categorização e hierarquização social. Nas palavras de Fanon (2008 [1952], p. 38): “sim, é preciso que eu vigie minha alocução, pois também é através dela que serei julgado... Dirão de mim com desprezo: ele não sabe sequer falar o francês!...”.

Essa relação entre língua e poder também se evidencia no uso da proficiência linguística como índice político - identificando categorias como cidadão, assimilado e indígena -, prática que foi recorrente em Angola, conforme o depoimento

92 Notícia disponível em <http://www.portalangop.co.ao/angola/pt_pt/noticias/lazer-e-cultura/2014/8/38/Fenacult-Escritor-realca-legado-Agostinho-Neto,e80e1dd0-93f8-485b-9945-9fab81ff8ce7.html> Acesso em 24 de jan. de 2016. 
relatado por Mingas (2000, p. 47): “o angolano deveria demonstrar saber falar correctamente a língua portuguesa e mostrar que tinha adquirido, no mínimo, a ilustração e os hábitos individuais e sociais dos portugueses, em especial, comer à mesa”. Essa mesma denúncia da relação entre o domínio da língua portuguesa e a categoria identitária de assimilado foi problematizada, esteticamente, por Uanhenga Xitu na obra O Mestre Tamoda: "Tamoda constitui um típico assimilado, cujos dois principais elementos utilizados para igualar-se aos portugueses e distinguir-se dos habitantes da sanzala são: o vestuário e a língua” (PINA; PINA, 2006, p. 162). Essa obra foi tomada como marco simbólico do processo político de reconhecimento - literário, acadêmico e institucional - da africanização do português em Angola (PINA; PINA, 2006).

Entre a Gramatiquinha de Mário de Andrade e os relatos feitos por Fanon e Mingas, existe uma cisão política a ser considerada: enquanto o primeiro se localiza em uma região entre o ficcional e o real, os outros referem-se a narrativas de experiência em que a vida humana era avaliada e julgada através da língua falada pelos sujeitos. Embora Mário de Andrade nos ajude a compreender as tensões políticas que se inscrevem nas disputas pela legitimação de um modo de falar, tornando a literatura uma arma política, os relatos de experiência e os testemunhos produzem efeitos de denúncia poderosos. Assim, enquanto a literatura pode "suavizar" certos embates por ser considerada "ficcional", autônoma e sem compromisso com o contexto de produção imediato, os relatos assumem uma outra potência, em que a relação com o real é discursivizada de uma outra maneira. Essa distinção pode ser teoricamente fundamentada a partir da concepção de Benjamin (1994, p. 201) sobre o papel da oralidade e da narrativa, similar aos provérbios: "o narrador retira da experiência o que ele conta: sua própria experiência ou a relatada pelos outros. E incorpora as coisas narradas à experiência dos seus ouvintes. O romancista segrega-se”.

No que tange à Linguística, esse campo de saber se consolidou no Brasil apenas nos anos 1970, sendo que a Associação Brasileira de Linguística foi criada em 1969. Contudo, preocupações menos sistematizadas em torno da descrição e normatização das brasilidades da língua portuguesa falada e escrita no Brasil remontam ao século XIX (com o romantismo literário), passando pelo contexto modernista e amadurecendo, academicamente, nos anos de Chumbo do período militar brasileiro (1964-1985). Sobre os esforços em torno da descrição e do reconhecimento do português brasileiro, podemos mencionar dois períodos emblemáticos: os anos 1920, com o surgimento de trabalhos variados que buscavam descrever as regionalidades linguísticas, e os anos 1970, com a construção dos primeiros grandes bancos de dados do português brasileiro. Dentre os primeiros, mencionamos os seguintes trabalhos: O Dialeto caipira (Amadeu Amaral, 1920), que versava sobre as especificidades do português do interior paulista; o Lin- 
guajar carioca (Antenor Nascentes, 1922), que abordava a variedade falada na cidade do Rio de Janeiro; a Língua do Nordeste (Mário Marroquim, 1934), que construiu um panorama linguístico da língua falada no nordeste; o Vocabulário pernambucano (Pereira da Costa, 1937), que apresentava o léxico regional do estado de Pernambuco; Estudos de dialetologia portuguesa: a linguagem de Goiás (José Teixeira, 1944); e A linguagem popular da Bahia (Édison Carneiro, 1951), só para mencionar alguns exemplos (CASTILHOS, 1972).

Sobre os bancos de dados sociolinguísticos, que visam registrar as variações do português brasileiro regionalmente, menciona-se a criação, nos anos 1970, do projeto Nurc (http://www.letras.ufrj.br/nurc-rj/), com sede no Rio de Janeiro e que teve como propósito descrever, em cinco regiões brasileiras, a variedade urbana culta do português brasileiro falado. De acordo com Silva (2006), dentre os objetivos estabelecidos para o projeto estava: levantar e sistematizar material linguístico da modalidade oral culta e produzir conhecimentos que pudessem ser aplicados pedagogicamente sobre a língua portuguesa brasileira culta, a partir de estudos empíricos. Aponta-se para a preocupação pedagógica presente no esforço de descrição do português culto brasileiro, de forma a atualizar os manuais de ensino com informações linguísticas contextualizadas, evitando a reprodução de representações abstratas (e lusitanas) de língua portuguesa. Além do Nurc, a partir dos anos 1970, uma série de outros bancos de dados foram construídos no Brasil, sob o escopo da sociolinguística, de acordo com Coelho et al. (2015) e Ataliba (s/d):

- PEUL - Programa de Estudos da Linguagem, no Rio de Janeiro (www. letras.ufrj.br/peul);

- VARSUL - Variação Linguística no Sul do Brasil (http://www.varsul.org. $\underline{\text { br); }}$

- Projeto sobre o Português Popular da Bahia (http://www.vertentes.ufba. br/home);

- Estudos Comparados do Português Brasileiro, Africano e Europeu (http:// www.concordancia.letras.ufri.br/);

- Português falado na região do semiárido Baiano (http://www2.uefs.br/ nelp/projetos.htm);

- ALIB - Atlas Linguístico do Brasil (http://twiki.ufba.br/twiki/bin/view/ Alib/WebHome);

- Programa de História do Português (UFBA, http://www.prohpor.org/);

- Projeto para a História do Português Brasileiro (várias universidades brasileiras). 
Ressalta-se que esse esforço acadêmico por registrar, descrever, documentar e analisar a funcionamento do português no contexto brasileiro levou à intensa produção de uma série de instrumentos linguísticos (gramáticas e dicionários) comprometidos com os usos concretos, embora sistematizados a partir de uma chave sociológica frágil. Dentre as gramáticas, menciona-se a publicação de oito volumes da Gramática do Português Falado Culto no Brasil. Importante frisar que tal gramática centrou-se na oralidade, em vez de focar dados de escrita, definindo a relação entre fala e escrita da seguinte maneira: "a língua falada e a língua escrita integram um mesmo sistema, diferenciando-se na frequência dos processos ou das categorias de que dispõem" (CASTILHOS, s/d, p. 12). Assim, o que diferencia ambas as modalidades não seria um certo preciosismo ou normativismo vinculado à escrita, mas a frequência de uso dos recursos linguísticos. A partir do levantamento dessa frequência contextualizada de fenômenos linguísticos, algumas deduções valorativas seriam tomadas em termos de maior ou menor adequação de certos usos linguísticos a determinados contextos de fala e/ou escrita. Além desses volumes, pode-se citar: Perini (1995), Bechara (1999), Neves (2000), Castilhos (2010) e Bagno (2011). Exemplos de dicionários incluem: Borba (1990) e Houaiss (2001).

A apresentação desse levantamento sobre os principais estudos envolvendo a descrição da língua falada e escrita no Brasil, atentando para a sua fragmentação regional e social, teve como objetivo ilustrar o processo de produção de conhecimento pela linguística sobre a brasilidade da língua, ajudando a legitimar uma diferenciação entre português brasileiro (PB) e europeu (PE) que carrega implicações políticas. Grande parte desses esforços fundamenta-se em motivações e inspirações estruturalistas (CASTILHOS, s/d), que definiram a língua a partir da sua fragmentação interna em níveis linguísticos. Embora haja uma tentativa de contextualização dos dados linguísticos pelo projeto, tal esforço resume-se à uma frágil descrição dos contextos e à tipificação dos “informantes” por categorias identitárias.

Reconhecemos, por um lado, o papel político dessa produção intensa de conhecimentos, pois ela ajudou a legitimar a brasilidade de usos linguísticos presentes na oralidade, distanciando-se, cada vez mais, do modelo lusitano e admitindo, embora com certa timidez, o papel da oralidade na construção da ideia de "culto". Por outro lado, tais estudos não problematizam a maneira como esses saberes linguísticos cristalizam o conceito de língua, a partir de uma visão estruturalista, e instauram novas diferenciações sociais através de classificações linguísticas. Acredita-se que, nesse aspecto, os estudos literários sobre língua podem contribuir para estremecer o cientificismo presente nas descrições linguísticas, atentando para a sua dimensão discursiva, histórica e política. Afinal, a língua-estrutura é produto das práticas linguístico-discursivas, e não o contrário 
(MAKONI; PENNYCOOK, 2006).

Em relação aos estudos linguísticos em Angola, Sassuco (cf. nesta obra) defende um processo de reconhecimento e validação do português angolano pelos acadêmicos angolanos. Diferentemente do Brasil, os bancos de dados do português angolano estão em processo de construção, sendo que a ideia de norma linguística que impera, em grande parte dos contextos institucionais, centra-se no modelo lusitano. Pesquisadores angolanos que têm descrito o português angolano em seus diferentes níveis linguísticos, considerando as influências das diferentes línguas africanas, incluem: Mingas (2000), que dissertou sobre as influências da língua kimbundu no português falado em Luanda; os trabalhos de Nzau (2011), que defendeu sua tese A Lingua Portuguesa em Angola, em que discute a angolanização do português; Gonçalves (2000), que tece aproximações entre aspectos linguísticos e literários de Angola e Moçambique; e Inverno (2005), que descreve singularidades da morfossintaxe do português angolano; dentre outros.

Além de pesquisas linguísticas angolanas que buscam descrever e legitimar o português falado em Angola, cabe mencionar trabalhos comparados que aproximam o português brasileiro do português angolano, buscando semelhanças entre as duas línguas. Tais estudos comparados são importantes, pois validam e reconhecem as heranças linguísticas africanas no Brasil. Exemplificando, tem-se os seguintes estudos: Angola e Brasil: vínculos linguísticos e afro-lusitanos (Lipski, 2008); Português Brasileiro, Português Moçambicano e as línguas crioulas de base portuguesa (Oliveira, 2008); Variedades linguísticas em contato: português angolano, português brasileiro e português moçambicano (Petter, 2008) e A indeterminação do sujeito no português angolano: uma comparação com o português do Brasil (Teixeira, 2011). Tais exemplos demonstram uma tendência de análise comparativa a partir de uma perspectiva estruturalista e descritiva, focalizando aspectos morfossintáticos. Considera-se, contudo, que uma perspectiva mais ampliada de língua, que a considere como prática social, poderia contribuir para uma compreensão política e histórica dos fenômenos linguístico-discursivos, incluindo as práticas estéticas.

Esta seção tematizou o papel político da Literatura e da Linguística, bem como do texto literário e dos usos linguísticos, na construção e naturalização de concepções de língua, bem como na validação de discursos nacionalistas. A seguir, atenta-se para o papel político do conceito de hibridização, exemplificando com situações literárias e linguísticas.

\section{Hibridizações linguísticas e relações de poder}

A título de ilustração do papel das teorizações literárias e linguísticas sobre as línguas, nos remetemos ao contexto russo dos anos 1920-1930, que esteve sob 
controle de Lênin e, posteriormente, de Stálin. Nesse contexto, dois intelectuais produziram concepções teóricas sobre a língua extremamente pertinentes para o debate pós-colonial contemporâneo: Iakubinskii e Bakhtin. Ambos defendiam que as línguas eram estratificadas socioideologicamente, em oposição à defesa da língua única, em que esta seria vista como uma construção política, alimentando o mito da unidade. Enquanto Iakubinskii defendia uma interpretação sociológica que considerava o caráter de classe da língua, em diálogo com a ideologia comunista e marrista, Bakhtin abandonou esse conceito político de classe em prol de uma visão aparentemente mais descritiva, conforme sinalizado por Lähteenmäkï (2006, p. 55):

o relato de Bakhtin pode ser considerado como puramente descritivo, ele estava completamente desinteressado dos mecanismos que possivelmente subjazem à estratificação de uma língua, enquanto Iakubinskii tem a intenção de explicar o fenômeno [...] dentro de uma língua nacional, com estruturas de classe de uma sociedade.

Essa diferença entre os autores, contudo, não significa que Bakhtin tenha abandonado as reflexões políticas sobre a diversidade linguística, em tempos em que a política linguística stalinista era a favor do reconhecimento de uma língua única, o russo. Suas reflexões sobre plurilinguismo, hibridização linguística, dialogismo e estratificação linguística - fortemente retomadas atualmente pelo campo linguístico - foram exploradas no contexto estético-literário, mediante a análise do gênero romanesco (BAKHTIN, 1934-1935). Aliás, foi em relação a esse gênero literário que Bakhtin propôs uma articulação radical entre arte e vida: "toda estratificação interna de cada língua em cada momento dado de sua existência histórica constitui premissa indispensável do gênero romanesco. E é graças a este plurilinguismo social e ao crescimento em seu solo de vozes diferentes que o romance orquestra todos os seus temas" (BAKHTIN, 1934-1935, p. 74). O que parece estar em questão, para Bakhtin e Iakubinskii, são as motivações - políticas, sociais, culturais ou estéticas - que levam à emergência do plurilinguismo. Se, por um lado, o alargamento do conceito de plurilinguismo, por Bakhtin, possibilita incorporar uma série de questões (como o conceito de dialogismo), por outro lado, a sua potência política pode ser, por vezes, estremecida, conforme percebe-se em análises linguístico-discursivas feitas por linguistas de inspiração bakhtiniana, que tendem a não problematizar, de forma radical, as relações de poder inscritas nos jogos de linguagem. Acreditamos que a opção de Bakhtin por uma proposta dialógica da linguagem, em detrimento de visões sociológicas de classe, expande as possibilidades políticas para se pensar outras categorias, além da classe social.

A abordagem bakhtiniana tem sido vinculada, no âmbito dos estudos literários, à área de estudos culturais, em diálogo com autores como Hall e Bhabha. 
Consideramos os escritos de Bakhtin pertinentes, pois trazem uma concepção de língua elaborada, que prioriza aspectos discursivos em detrimento de estruturais e formais, diferentemente da visão sugerida por Lähteenmäkï (2006). Ou seja, trata-se de considerar as línguas em relação às vozes sociais contextualizadas sócio-historicamente. Assim, o plurilinguismo não seria um conjunto de línguas unitárias, mas um complexo internamente dialogizado de vozes sociais e horizontes axiológicos. Conforme visto, Bakhtin (1934-1935, p. 129) explora o conceito de dialogismo a partir do romance: "se o romancista perde o terreno linguístico do estilo em prosa [...] se for surdo para a bivocalidade orgânica e a dialogicidade interna do discurso vivo em transformação, ele nunca compreenderá nem realizará as possibilidades e os problemas reais do gênero romanesco". Trata-se, com isso, de inscrever as relações de poder nas relações dialógicas, em que a relação entre os sentidos se torne politizada (SEVERO, 2013).

Essa dialogicidade das vozes sociais caracteriza o plurilinguismo e a hibridização, seja literária, seja orgânica. Enquanto a primeira diz respeito a uma mistura estilística, criada pelo autor, de vozes sociais no interior do romance; a segunda, de natureza involuntária, diz respeito às fusões de vozes sociais - e de línguas - na esfera do mundo da vida. É assim que "uma hibridização involuntária, inconsciente, é uma das modalidades mais importantes da existência histórica e das transformações das linguagens" (BAKHTIN, 1934-1935, p. 156). Dessa forma, são as línguas e vozes sociais (discursos) que estão sujeitos à hibridização a partir de sua relação (dialógica) com outras vozes e línguas. Tal relação, importante frisar, é de natureza política (FOUCAULT, 1999).

No âmbito dos estudos linguísticos, a categoria de hibridização tem sido utilizada para desconstruir conceitos teóricos que têm sido usados para justificar políticas autoritárias e segregacionistas, como a ideia de uma língua "pura" ou homogênea. O conceito de hibridismo, contudo, é delicado, pois carrega sentidos ambivalentes: ele pode tanto reforçar a visão do colonizador ao sustentar a manutenção da língua ou traços culturais dominantes; como pode funcionar como um lugar de inscrição das vozes e discursos de resistência, em um processo de "nativização" (MATA, 2009; NZAU, 2011; BHABHA, 2003). Além disso, a ideia de hibridismo pode reforçar o mito da pureza, uma vez que poderia pressupor a existência de elementos supostamente não híbridos. A despeito de tais diferenças, consideramos esse conceito como politicamente relevante, pois realça os jogos políticos que giram em torno da (des)construção de categorias linguístico-discursivas homogêneas, colocando em tela outras formas de representação - calcadas nos "saberes negados" (BHABHA, 2003) - das práticas linguístico-discursivas coloniais. Nos alinhamos à perspectiva de que os elementos hibridizados e hibridizáveis fazem parte de um processo contínuo de tradução cultural e de abertura de novos objetos políticos, sendo "sempre inscritos diferentemente pelas relações de 
poder - sobretudo as relações de dependência e subordinação sustentadas pelo próprio colonialismo" (HALL, 2009, p. 34). Assim, o uso do termo pelo "dominante" para legitimar relações de poder que o privilegiam deve ser compreendido diferentemente do emprego do mesmo termo pelos "dominados". Nas palavras de Bhabha (2003, p. 20-21), "a articulação social da diferença, da perspectiva da minoria, é uma negociação complexa, em andamento, que procura conferir autoridade aos hibridismos culturais que emergem em momentos de transformação histórica". Juntamente com Bhabha, reconhecemos o uso dos hibridismos como práticas discursivas contra-hegemônicas.

Exemplificando os usos do conceito de hibridismos em reflexões de políticas linguísticas, no âmbito do universo geopolítico recortado pela língua portuguesa, Severo (2011) descreveu e analisou as hibridizações linguísticas envolvendo o português e o tétum em Timor Leste, ex-colônia portuguesa que se tornou independente de Portugal, em 1975, e da Indonésia, em 2002. Trata-se de um contexto extremamente plurilíngue, em que as pessoas mesclam essas línguas em diferentes esferas socioideológicas de uso. Esse plurilinguismo internamente dialogizado tem sido tensionado por políticas nacionais que oficializaram apenas a língua portuguesa e a língua tétum. Situação semelhante tem sido presenciada em países africanos.

A esse respeito, a mesma autora (2011a) analisou o papel político das hibridizações no contexto angolano, país que se tornou independente de Portugal em 1975 após longas lutas violentas pela libertação. Tais lutas mobilizaram a existência de três partidos: o Movimento Popular de Libertação da Angola (MPLA), a Frente Nacional de Libertação da Angola (FNLA) e a União Nacional para a Independência Nacional de Angola (UNITA). Com a chegada do MPLA ao poder, houve a oficialização do português e o reconhecimento das línguas angolanas como nacionais. Assim, o reconhecimento do português como língua oficial não foi fruto de uma decisão popular, mas surgiu como "produto histórico duma cristalização identitária em pelo menos uma parte consistente do território" (CAHEN, 2005, p. 41). Por outro lado, o plurilinguismo angolano implica a coexistência de vozes sociais (e línguas) que estabelecem entre si relações tanto de tensões como de coadunações. Assim, em Angola, presencia-se tanto defensores de um reconhecimento oficial - com políticas mais ostensivas - das línguas angolanas, como há aqueles que temem que o fortalecimento de certas línguas angolanas possa reforçar o poder de certas etnias, em detrimento de outras, estremecendo a ideia de unidade nacional. Reitera-se, aqui, os usos políticos da articulação feita entre etnia e língua, em que cada etnia seria designada por uma língua. Esse aspecto é problematizado por Makoni e Meinhof (2004), que defendem que a ideia de língua, tal como compreendemos, é uma construção política, especialmente quando enquadram grupos de determinadas maneiras no contexto 
colonial africano.

As hibridizações linguísticas em Angola foram analisadas por Severo (2011a) em relação ao contexto literário, nas obras de Luandino Vieira e Agostinho Neto. Nesse contexto, foram vistos os significados inscritos em diferentes hibridizações linguísticas, que envolveram desde elementos morfossintáticos até elementos pragmáticos e discursivos. Em termos de hibridizações orgânicas, vinculadas à esfera da vida, salientam-se as fusões entre a língua portuguesa e línguas angolanas, conforme ilustram trabalhos que buscam reconhecer e legitimar o português angolano. À guisa de ilustração, o escritor Ruy Duarte (2008, p. 49) - que desconhece as línguas africanas e, portanto, tem uma posição exotópica em relação a essas línguas - compartilha sua sensibilidade linguística a respeito das influências africanas na língua portuguesa oral: "[...] tenho tentado compensar a incompetência que me atribuo no domínio das línguas outras investindo uma atenção redobrada à sinuosidade, às precipitações, aos atalhos da língua portuguesa falada pelas populações com quem lido". Situação linguística semelhante ocorreu no Brasil, uma vez que, desde o século XIX, busca-se reconhecer as influências e heranças de línguas indígenas e africanas no português falado e escrito no Brasil. É assim que, em Angola ou Brasil, “a pilhagem ou roubo da língua portuguesa pelo colonizado mostra que a africanização, perversamente, se institui e processa no interior do instrumento comunicativo, num processo transformativo e nativizante" (LEITE, 1998, p. 33).

Se, por um lado, o reconhecimento e validação do português brasileiro ou português angolano reforçam posturas nacionalistas, fortalecendo a imagem de uma comunidade - brasileira ou angolana - que compartilha recursos simbólicos e culturais (ANDERSON, 2008), por outro lado, essa ideia de comunidade, que funda o conceito de nação e de nacionalismo, contesta e resiste ao domínio político, cultural e simbólico dos ex-colonizadores por meio da construção de um discurso "local". A ideia de "local", contudo, deve ser vista com relativa cautela, pois é defendida por uma pequena elite política que assumiu o poder das ex-colônias, seja no Brasil ou em Angola, reproduzindo, muitas vezes, cisões sociais, estereótipos e hierarquias construídas no seio do projeto colonial e muitas vezes legitimadas por saberes acadêmicos e institucionalizados (SEVERO; MAKONI, 2015; CARVALHO, 2008). Ilustrativa dessas relações de poder é a observação feita por Ruy Duarte de Carvalho (2008, p. 38) a respeito da perspectiva da população de pastores do sudoeste angolano sobre os governantes angolanos: "muitas vezes entendem o poder de Luanda como uma prolongação do poder dos brancos, agora sem a taxa do 'imposto' mas também sem comércio". Assim, as políticas de diversidade linguística defendidas por certa elite política - em prol da defesa de interesses "locais" - pode, por vezes, reforçar estereótipos de "autenticidade" que, na prática, não dialogam com a perspectiva das pessoas que não 
compartilham os mesmos significados simbólicos e posições de poder: "o que as elites intelectuais africanas definem como autêntico, não o é do ponto de vista dos pobres que vivem nas áreas rurais" (MAKONI; MEINHOF, 2004, p. 201).

\section{Palavras finais}

Este capítulo teve como objetivo problematizar a analisar o papel político da língua portuguesa em duas esferas discursivas próximas, embora por vezes antagônicas: Literatura e Linguística. Para tanto, foram consideradas, de forma comparada, as conjunturas de Angola e Brasil. Buscou-se refletir sobre, por um lado, a maneira como esses campos do saber constroem discursos sobre as línguas de forma a reconhecer significados políticos e culturais importantes para a construção de uma ideia de comunidade ou de pertencimento, seja em termos de nacionalismo, seja em prol da manutenção da diversidade. Por outro lado, o capítulo explorou o conceito de hibridismo linguístico, a partir das reflexões de Bakhtin, com fins de atestar o papel político do reconhecimento das hibridizações sofridas pela língua portuguesa, no Brasil e em Angola, constituindo línguas que apresentam traços linguísticos das línguas locais (indígenas e/ou africanas) e, sobretudo, que ecoam as vozes sociais do povos que foram historicamente marginalizados de diferentes maneiras: pela colonização lusitana e, posteriormente, pelo surgimento de uma elite local.

Defende-se que a reinvenção de uma memória que foi fortemente afetada, embora não unicamente, pela experiência colonial deve ser perpassada - no embalo das reflexões pós-coloniais contemporâneas - pela problematização de categorias teóricas que seguem um modelo explicativo baseado em exemplos e situações europeias e, portanto, distantes das realidades (ex-)colonizadas que buscam uma emancipação política, cultural e intelectual. Mais especificamente no contexto acadêmico, por um lado, essa missão de revisão teórica se coloca urgente - pois leva a um reconhecimento e valorização dos saberes e dos povos "locais" -, por outro lado, a reconfiguração de uma memória descolonizada passa por "longas conversas, sem pressas e com dezenas de pessoas [as diferentes populações envolvidas] ao longo de muitos meses. E talvez, ainda assim, só se possam reter monossílabos. E não todos" (CARVALHO, 2008, p. 62).

Defendemos que é preciso perseguir tais monossílabos - seja na esfera estética, seja na esfera cotidiana -, em busca de ressignificações que afetem, inclusive, a maneira como os saberes linguísticos e literários têm discursivizado o plurilinguismo e a pluridiscursividade. Ademais, é preciso que o Brasil, no processo de revisão de sua memória colonial, possa também aprender e dialogar com as experiências e lutas angolanas em busca da emancipação cultural, epistêmica, 
política e estética.

\section{Referências}

ABDALA JÚNIOR, B. (Org.). Margens da cultura: mestiçagem, hibridismo e outras misturas. São Paulo: Boitempo, 2004.

ALENCASTRO, L. F. O trato dos viventes: formação do Brasil no Atlântico Sul. São Paulo: Companhia das Letras, 2000.

BAGNO, M. Gramática pedagógica do português brasileiro. São Paulo: Parábola, 2011.

BAKHTIN, M. Arte e responsabilidade (1919). In: Estética da criação verbal. Tradução de Paulo Bezerra. 4. ed. São Paulo: Martins Fontes, 2003.

- Questões de literatura e de estética: a teoria do romance. Tradução de Carlos Vogt e Eny Orlandi. 4· ed. São Paulo: Unesp, 1998.

BECHARA, E. Moderna gramática portuguesa. 37. ed. Rio de Janeiro: Editora Lucerna, 1999.

BEMBE, M. D. Os vectores da construção da nação angolana e a função do Estado. Mulemba, vol. III, n. 6, p. 167-183, 2013.

BENJAMIN, W. O narrador: considerações sobre a obra de Nikolai Leskov. In: Magia e técnica, arte e política: ensaios sobre literatura e história da cultura. São Paulo: Brasiliense, 1994.

BHABHA, H. K. O local da cultura. Belo Horizonte: UFMG, 2003.

BORBA, F. S. et al. Dicionário gramatical de verbos. São Paulo: Unesp, 1990.

CAHEN, M. Luta de emancipação anti-colonial ou movimento de libertação nacional? Processo histórico e discurso ideológico - o caso das colônias portuguesas e de Moçambique em particular. Africana Studia, n. 8, p. 39-67, 2005.

CARVALHO, R. D. A câmara, a escrita e a coisa dita... fitas, textos e palestras. Lisboa: Edições Cotovia, 2008.

CASTILHO, A. T. Nova Gramática do Português Brasileiro. São Paulo: Contexto, 2010.

CASTILHOS, A. Rumos da dialetologia portuguesa. ALFA, n. 18/19, p. 115-153, 1972. Disponível em: <seer.fclar.Unesp.br/alfa/article/viewFile/3512/3285>. Acesso em: 10 out. 2011. 
CASTRO, Y. P. Falares Africanos na Bahia: um vocabulário Afro-Brasileiro. Rio de Janeiro: Topbooks Editora e Distribuidora de Livros, 2001.

. Desafios no estudo da língua falada. Museu da Língua Portuguesa. s.d. Disponível em: <http://www.museudalinguaportuguesa.org.br/files/mlp/texto 37.pdf $>$. Acesso em: 23 jan. 2016.

COELHO, I. L.; GÖRSKI, E. M.; NUNES DE SOUZA, C. M.; MAY, H. Para conhecer sociolinguística. São Paulo: Contexto, 2015.

CUNHA, A. "Processo dos 50": memórias da luta clandestina pela independência de Angola. Revista Angolana de Sociologia, n. 8, 2011. Disponível em: <http://ras.revues. org/543\#ftn3>. Acesso em: 28 jan. 2016.

DEUMERT, A. Imbodela zamakhumsha - reflections on standardization and destandardization. Multilingua, n. 29, p. 243-264, 2010.

ERRINGTON, J. Colonial linguistics. Annual Review of Anthropology, v. 30, p. 19-39, 2001.

FARDON, R.; FURNISS, G. African languages, development and the state. London: Routeledge, 1993.

FOUCAULT, M. A história da sexualidade I: A vontade de saber (1977). 13. ed. Rio de Janeiro: Graal, 1999. A ordem do discurso. São Paulo: Loyola, 1996.

GLISSANT, E. El discurso antillano. Caracas: Monte Ávila, 2005.

GONÇALVES, P. Para uma aproximação língua-literatura em português de Angola e Moçambique. Via atlântica, n. 4, out. 2000.

HALL, S. Da Diáspora: Identidades e Mediações Culturais. Belo Horizonte: UFMG, 2009.

HOUAISS, A.; VILLAR, M. S.; MELLO FRANCO, F. M. Dicionário Houaiss da língua portuguesa. Rio de Janeiro: Objetiva, 2001.

INVERNO, L. A transição de Angola para o português vernáculo: estudo morfossintáctico do sintagma nominal. In: CARVALHO, A. (Org.). Português em contacto. Madrid: Iberoamericana; Frankfurt: Editorial Vervuert, 2005.

IRVINE, J. Subjected words: african linguistics and the colonial encounter. Language and Communication, n. 28, p. 323-324, 2008.

LÄHTEENMÄKÏ, M. Da crítica de Saussure por Voloshinov e Iakubinski. In: FARACO, C. A.; TEZZA, C.; CASTRO, G. (Org.). Vinte ensaios sobre Mikhail Bakhtin. Rio de Janeiro: Vozes, 2006. p. 125-132. 
LEITE, A. M. Oraliades \& escritas nas literaturas africanas. Lisboa: Edições Colibri, 1998.

LIPSKI, J. Angola e Brasil: vínculos linguísticos afro-lusitanos. Veredas, n. 9, p. 83-98, 2008.

MAKONI, S.; PENNYCOOK, A. (Org.). Disinventing and Reconstituting Languages. Clevedon: Multilingual Matters, 2006.

MAKONI, S.; MEINHOF, U. Western perspectives in applied linguistics in Africa. AILA Review, n. 17, p. 77-105, 2004.

MARIANI, B. S. C. Políticas de colonização lingüística. Letras (UFSM), Santa Maria, v. 1, p. 73-82, 2006.

MATA, I. No fluxo da resistência: a literatura, (ainda) universo da reinvenção da diferença. Gragoatá, Niterói, n. 27, p. 11-32, 2009.

MENDONÇA, R. A influência africana no português do Brasil. Rio de Janeiro: Sauer, 1933.

NZAU, D. G. N. A lingua portuguesa em Angola: um contributo para o estudo da sua nacionalização. 2011. Tese (Doutorado em Letras) - Universidade da Beira Interior, Covilhã, 2011. Disponível em: <http://ubibliorum.ubi.pt/handle/10400.6/1844>. Acesso em: 18 set. 2016.

OLIVEIRA, M. Português brasileiro, português moçambicano e as línguas crioulas de base portuguesa. Veredas, n. 9, p. 99-114, 2008.

PERINI, M. A. Gramática descritiva do português. São Paulo: Editora Ática, 1995.

PETTER, M. T. Variedades linguísticas em contato: português angolano, português brasileiro e português moçambicano. 2008. Tese (Livre-docência) - Universidade de São Paulo, São Paulo, 2008.

PHILLIPSON, R. Linguistic imperialism. Oxford: Oxford University Press, 1992.

PINTO, E. P. A gramatiquinha de Mário de Andrade: texto e contexto. São Paulo: Duas Cidades, 1990.

PINA, A. A.; PINA, J. C. "Mestre" Tamoda, de Uanhenga Citu: uma caricatura da assimilação do colonizado angolano. Graphos, João Pessoa, v. 8, n. 1, p. 159-170, 2006.

RAJAGOPALAN, K. Por uma lingüística crítica: linguagem, identidade e a questão ética. 3. ed. São Paulo: Parábola, 2008.

RICOEUR, P. Hermeneutics and the human sciences: essays on language, action, and interpretation. Cambridge: Cambridge University Press, 1981.

SAID, E. Cultura e imperialismo. São Paulo: Companhia das Letras, 1995. 
. Representing the colonized: anthropology's interlocutors. Critical Inquiry, n. 15, v. 2, p. 205-225, 1989 .

SEVERO, C. G.; MAKONI, S. B. Políticas linguísticas Brasil-África: por uma perspectiva crítica. Florianópolis: Insular, 2015.

SEVERO, C. G. Questões de língua, identidade e poder: hibridismos em Timor Leste. Revista Brasi n ra de Linguística Aplicada, v. 11, p. 95-113, 2011.

. Línguas e discursos: heterogeneidade linguístico-discursiva e poder em Angola. Veredas, v. 15, p. 19-46, 2011.

. Bakhtin e Foucault: apostando em um diálogo. In: PAULA, L.; STAFUZZA, G. B. (Org.). Círculo de Bakhtin: pensamento interacional. Campinas: Mercado de Letras, 2013. p. 143-166. (Série Bakhtin Inclassificável, v. 3).

SHOHAT, E.; STAM, R. Do eurocentrismo ao policentrismo. In: - (Org.). Crítica da imagem eurocêntrica: multiculturalismo e representação. São Paulo: Cosac Naify, 2006. p. 37-58.

SILVA, L. A. Projeto NURC: Histórico. In: Linha D’água, n. 10, p. 83-99, 1996.

TEIXEIRA, E. S. P.; ALMEIDA, N. L. F. A indeterminação do sujeito no português angolano: uma comparação com o português do Brasil. Papia, Brasília, DF, v. 21, p. 99111, 2011.

VELLOSO, M. P. Os intelectuais e a política cultural do Estado Novo. Rio de Janeiro: Centro de Pesquisa e Documentação de História Contemporânea do Brasil, 1987.

ZOUNMÈNOU, M. V. Conhecimento indígena e tradições orais em Zulu (África do Sul) e Hun (Benin). In: HOUTONDJI, P. J. (Org.). O antigo e o moderno: a produção do saber na África contemporânea. Mangualde: Edições Pedago; Luanda: Edições Mulemba, 2012. 
